\title{
ANÁLISE DA ADIÇÃO DA CINZA GASEIFICADA DE CARVÃO MINERAL PULVERIZADO NA CERÂMICA VERMELHA A PARTIR DO TESTE DE ABSORÇÃO DE ÁGUA
}

\author{
G C. MENDONÇA ${ }^{1}$, C. C. FERREIRA ${ }^{1}$ \\ ${ }^{1}$ Universidade Federal do Pampa \\ e-mail para contato: cristiano.unipampa@gmail.com
}

\begin{abstract}
RESUMO - O presente trabalho avalia a fabricação de produtos cerâmicos destinados à construção civil através da adição, na argila, de cinza leve procedente da gaseificação do carvão mineral. As matérias-primas foram submetidas a testes de caracterização química por fluorescência de raios-X e preparadas em cinco diferentes formulações compostas: de argila in natura (A0), argila in natura mais adição de 5\% (CG5), 10\% (CG10), 20\% (CG20) e 30\% (CG30). O processo de fabricação dos corpos de prova ocorreu por prensagem e a secagem foi realizada de modo natural e artificial, ao final desse processo os corpos de prova foram sinterizados na temperatura de $800^{\circ} \mathrm{C}$. A análise de desempenho dos produtos ocorreu através da realização de testes físicos como: absorção de água, porosidade aparente e massa específica, conforme as normas da M-CIENTEC 0-22, 0-23 e 024 (1995). Os valores médios de absorção variaram entre 14,11\% (A0) e 26,53\% (CG30). Esses índices mostraram que $80 \%$ das formulações apresentaram absorção de água dentro das faixas de aceitação da NBR 15270-1 (2005). Ao final observou-se que através do ensaio de absorção de água que é possível fabricar tijolos maciços e blocos de vedação. A fabricação de telhas é possível apenas as formulações (A0), (CG5) e (CG10) conforme NBR 15310 (2009).
\end{abstract}

\section{INTRODUÇÃO}

De acordo com o trabalho de Soares et al. (2016) a gaseificação é uma alternativa conveniente para a produção de energia a partir de resíduos sólidos. Os coprodutos oriundos da gaseificação podem ser aproveitados para diversos fins, desde síntese de produtos químicos até aditivos para cimentos (PELLEGRINO, 2006).

A cinza volante (ou leve) é composta por sílica, óxidos metálicos e uma alta quantidade de carbono, este elevado índice está relacionado ao processo de gaseificação que foi realizado via leito fluidizado (DIAS, 2017). De acordo com Barbosa (2016) a gaseificação via leito fluidizado se caracteriza pela formação de um leito de biomassa em suspensão produzido pelo fluxo de ar forçado, sendo vantajoso pela distribuição uniforme da temperatura na região da gaseificação.

A adição de resíduos em materiais cerâmicos é uma prática vantajosa, Guilhon et al. (2016) apontam que o maior desafio das indústrias é conciliar a viabilidade econômica da 
viabilidade ecológica. Dantas (2008), destaca também que a incorporação de resíduos na cerâmica vermelha é capaz de trazer benefícios adicionais na melhoria do processo e nas características do produto final. A absorção de água é uma propriedade muito importante do material cerâmico, pois a partir dela é possível observar o seu comportamento, além dela estar diretamente relacionada com a porosidade aparente e massa específica aparente, atuando também como um parâmetro de qualidade do material cerâmico para a construção civil (PNHEIRO, 2010).

Diante disso, o objetivo dessa investigação é avaliar a incorporação da cinza volante proveniente da gaseificação do carvão mineral em argila a partir do teste de absorção de água.

\section{MATERIAIS E MÉTODOS}

A argila utilizada foi coletada em uma pequena olaria localizada na região de Bagé RS, essa argila tem característica caulinita e não passou pelo processo de sazonamento, ou seja, contém significativos índices de material orgânico. A amostra de argila coletada foi moída, quarteada e peneirada onde a fração passante na peneira de 100 mesh foi a utilizada na pesquisa. Já a cinza leve gaseificada foi coletada no Laboratório de Energia e Carboquímica da Universidade Federal do Pampa, Campus Bagé - RS. A amostra de cinza foi quarteada e, não houve a necessidade de ser moída e peneirada pois sua granulometria estava análoga a 100 mesh, assemelhando-se assim com a da argila.

Aproximadamente $10 \mathrm{~g}$ dos dois materiais foram submetidos a caracterização química de fluorescência de raios-X. As amostras de argila in natura e resíduo nas proporções prédeterminadas foram misturadas e homogeneizadas.

Após as formulações foram umidificadas até atingir $5 \%$ em peso (massa de umidade/massa seca). Em seguida foram armazenadas em sacos plásticos, e permaneceram em repouso por 24 horas para ocorrer a homogeneização da umidade em toda a mistura. As formulações foram pré-determinadas e preparadas com adições de 5, 10, 20 e 30\% de cinza leve gaseificada na argila conforme (Tabela 1).

Tabela 1 - Formulações cerâmicas investigadas (\% em peso)

\begin{tabular}{|c|c|c|}
\hline Formulação & Argila & $\begin{array}{c}\text { Cinza leve } \\
\text { gaseificada }\end{array}$ \\
\hline \hline A0 & 100 & 0 \\
\hline \hline CG5 & 95 & 5 \\
\hline CG10 & 90 & 10 \\
\hline CG20 & 80 & 20 \\
\hline \hline CG30 & 70 & 30 \\
\hline
\end{tabular}

As massas cerâmicas foram prensadas em uma prensa Atlas Series Laboratory Hydraulic Press de 5 toneladas. Após a conformação os corpos de prova foram submetidos a secagem natural, em temperatura ambiente por aproximadamente 24 horas e a secagem artificial a $110^{\circ} \mathrm{C}$ por 24 horas. Em seguida os corpos de prova foram queimados em um forno elétrico da marca SANCHIS, com um patamar de $80^{\circ} \mathrm{C}$ por hora. Ao atingir a temperatura 
desejada $\left(800^{\circ} \mathrm{C}\right)$ permaneceu no forno por 3 horas. Nos produtos obtidos foram determinados: a absorção de água [M-CIENTEC 0-22 (1995)], a porosidade aparente [MCIENTEC 0-23 (1995)] e a massa específica aparente [M-CIENTEC 0-24 (1995)]. Os testes foram feitos da seguinte forma: primeiramente, os corpos de prova foram fervidos por 2 horas e após este período esperou-se atingir a temperatura ambiente (Figura 1A), em seguida, foram pesados em uma balança hidrostática - Massa imersa (Figura 1B), nesta etapa eles foram secos com um pano de algodão e pesados em uma balança eletrônica - Massa úmida (Figura $1 \mathrm{C}$ ), por fim foram colocados na estufa a $110^{\circ} \mathrm{C}$ por, aproximadamente, 15 horas e pesados novamente na balança analítica - Massa seca.

Figura 1 - Teste de absorção de água, porosidade aparente e massa específica em corpos de prova cerâmicos

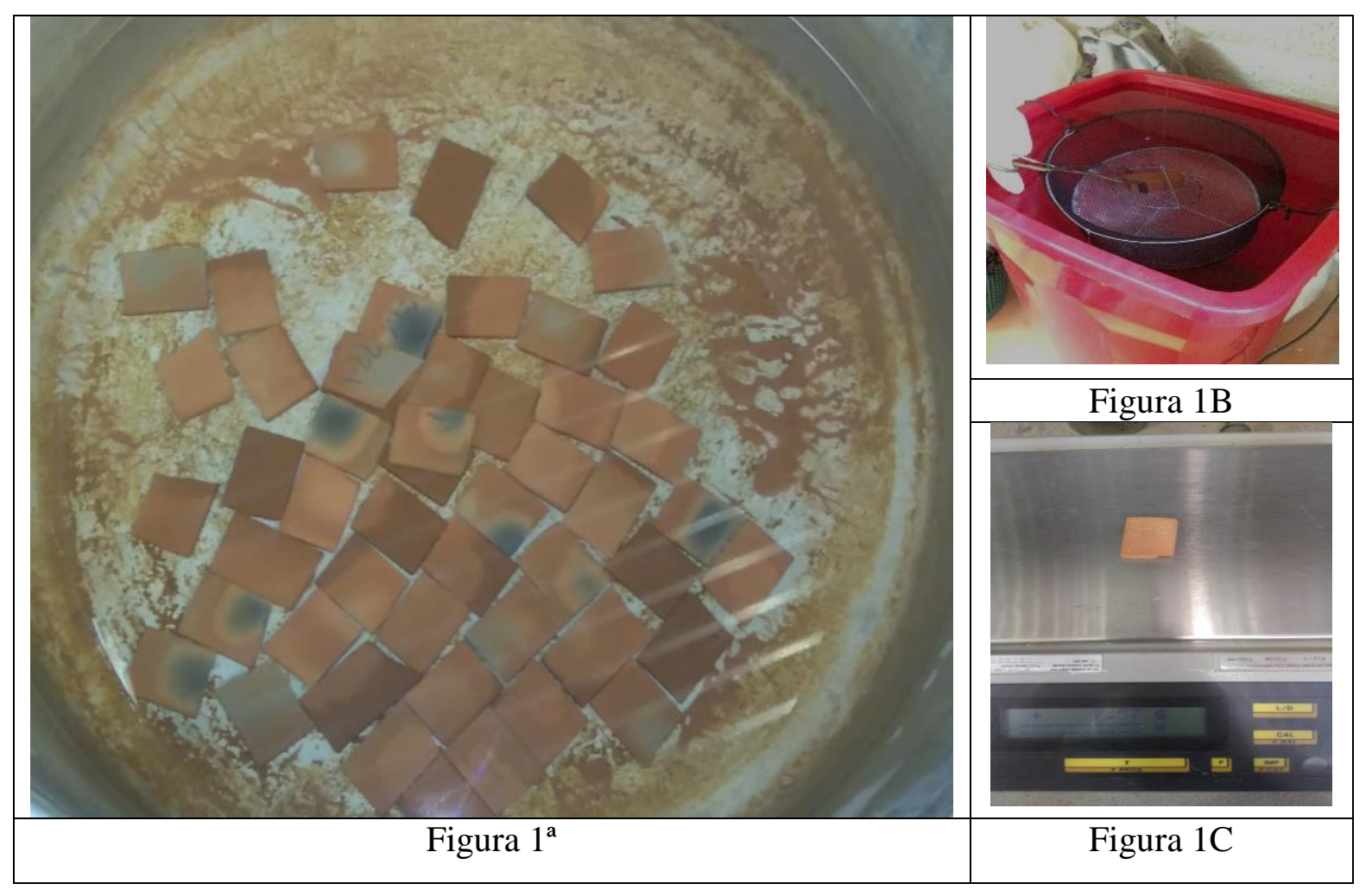

\section{RESULTADOS E DISCUSSÃO}

A Figura 2 apresenta o resultado obtido da absorção de água das formulações investigadas. Nota-se que ocorreu um aumento da absorção de água a medida em que se acrescentou mais cinza na formulação, além do mais, o teste também revelou que as formulações A0, CG5, CG10 e CG20 podem serem utilizadas para fabricação de tijolos e blocos cerâmicos $(8 \%$ < absorção de água < 22\%), no entanto, a CG30 obteve índice acima do valor recomendado. Também se avaliou a possibilidade de uso para telhas e, nesta, somente as formulações A0, CG5 e CG10 se enquadraram dentro das especificações da norma de (absorção de água $<20 \%$ ). 
Figura 2 - Gráfico do resultado da absorção de água

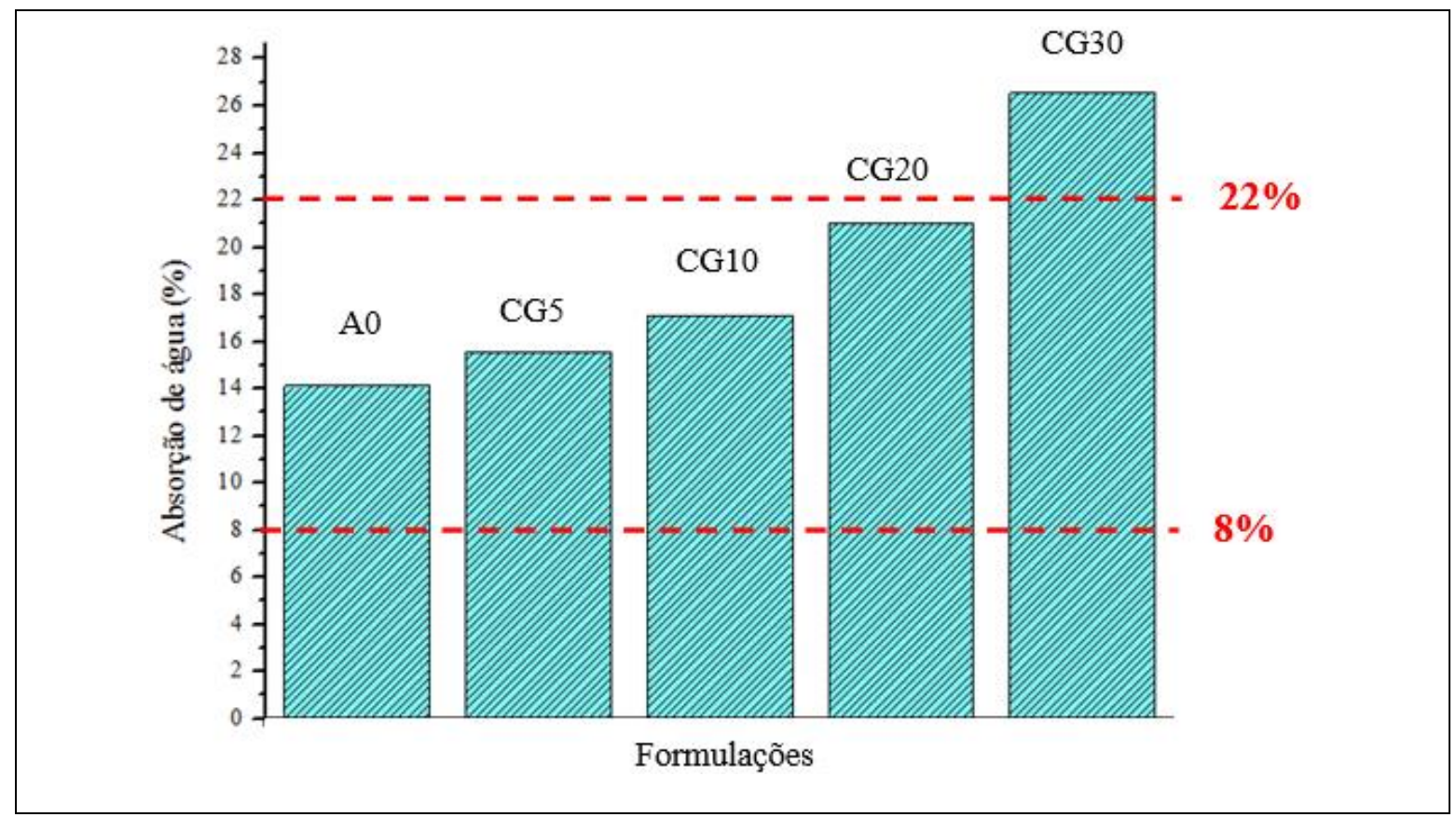

A Figura 3 mostra o resultado de porosidade aparente dos corpos cerâmicos queimados na temperatura de $800^{\circ} \mathrm{C}$ e, observa-se que apresentou comportamento análogo ao da absorção de água, apenas a formulação CG30 apresentou porosidade aparente acima do recomendado pelo IPT (1985 apud AMORIN, 2007, p. 74), que informa que os limites devem estar entre $17 \%$ e $35 \%$.

Figura 3 - Gráfico do resultado da porosidade aparente

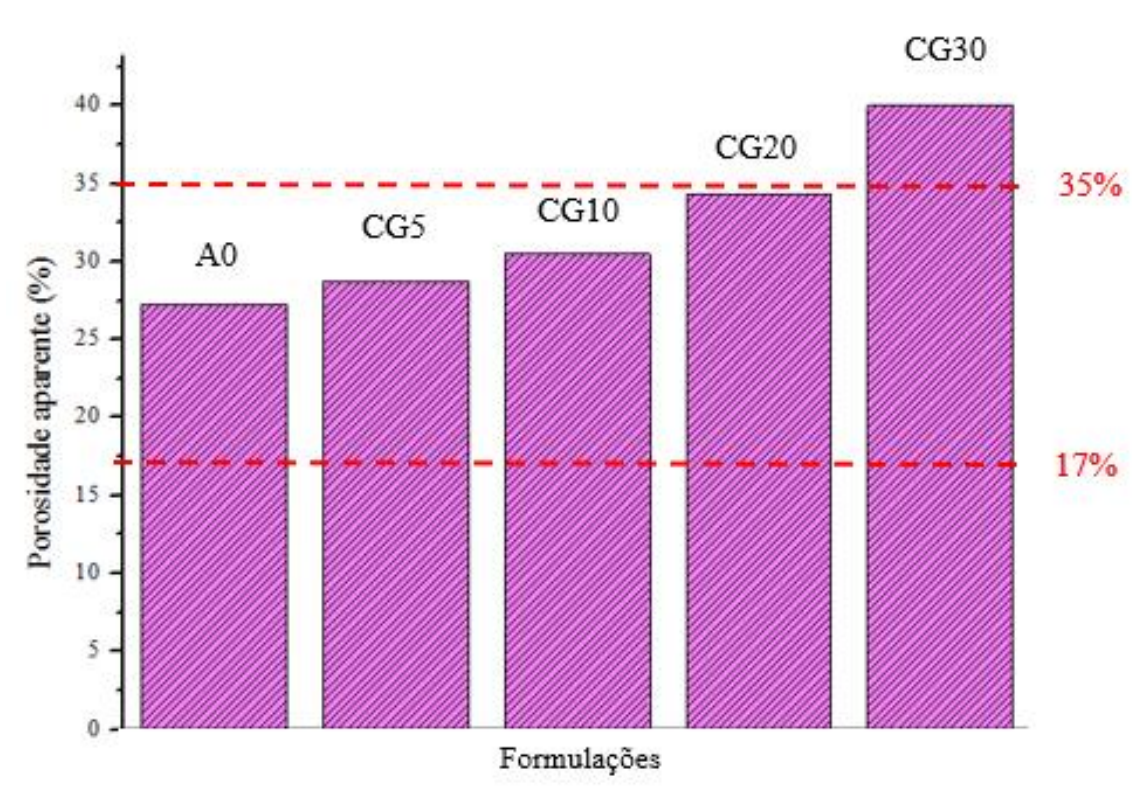


A massa específica aparente dos corpos de prova é mostrada na Figura 4. A adição da cinza resultou em uma menor densificação conforme aumenta a porcentagem de cinzas. De acordo com IPT (1985 apud AMORIN, 2007, p. 74), a massa específica aparente deve ser acima de $1,7 \mathrm{~g} / \mathrm{cm}^{3}$, no entanto, as formulações CG20 e CG30 não atingiram os índices mínimos.

Figura 4 - Gráfico do resultado da massa específica aparente

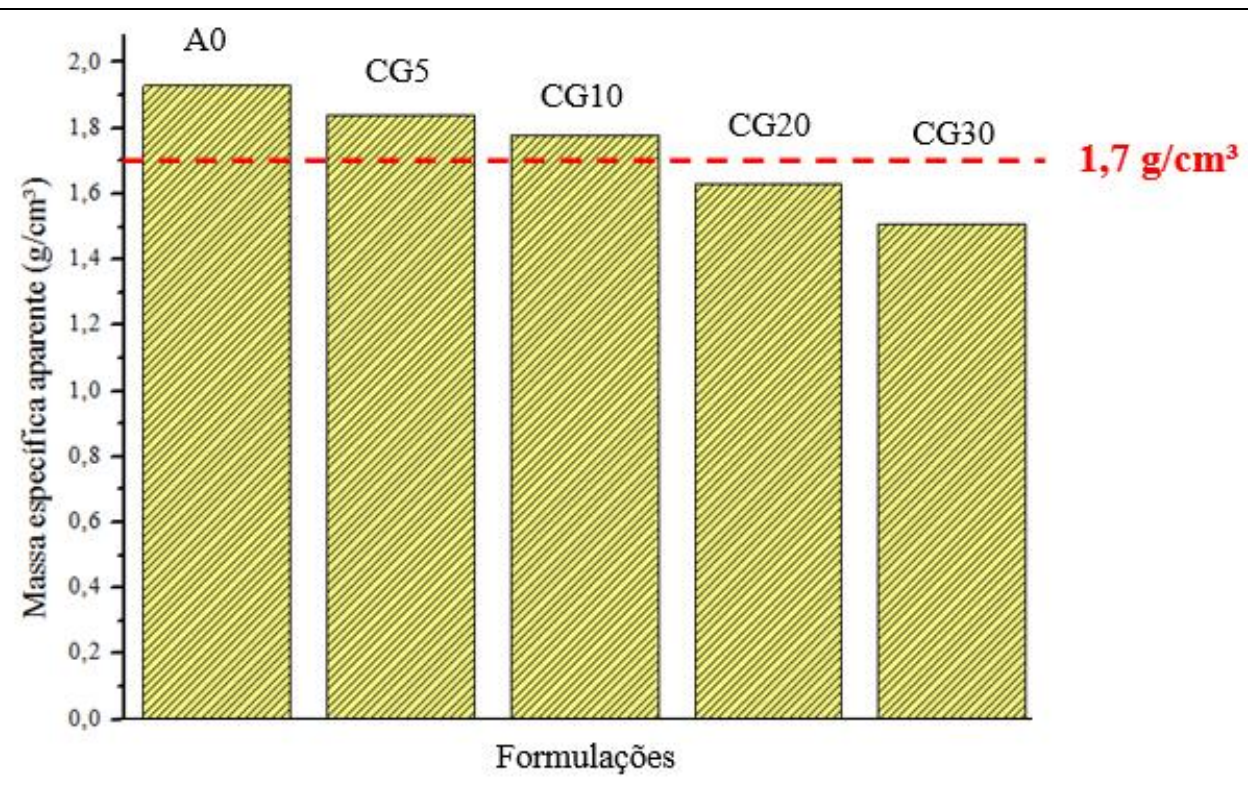

\section{CONCLUSÕES}

Conclui-se que o resíduo proveniente da gaseificação do carvão mineral pulverizado pode ser incorporado a argila in natura com o propósito de fabricar produtos como tijolos e blocos de vedação em relação a análise da absorção de água nas formulações A0, CG5, CG10 e CG20\%. Deve-se destacar que quanto maior o percentual de cinza na argila maior será a absorção de água.

\section{REFERÊNCIAS}

AMORIM, F. R. Co-processamento de dregs em argila para produção de cerâmica vermelha. 2007. Dissertação (Mestrado em Saneamento) - Universidade Federal de Minas Gerais, Belo Horizonte, MG, 2007. 
BARBOSA, Katia; SILVA, J. D. Análise Fluidodinâmica da Região de Gaseificação de um Gaseificador de Leite Fluidizado. Revista de Engenharia e Pesquisa Aplicada, v. 2, n. $1,2016$.

DANTAS, A. P. A. Utilização de resíduos de rochas ornamentais na produção de cerâmica branca. 2008. 96 f. Dissertação (Mestrado em Engenharia Mecânica) - Programa de Pós-Graduação em Engenharia Mecânica. Universidade Federal do Rio Grande do Norte.

DIAS, Yan Resing et al. CARACTERIZAÇÃO PRÉVIA DAS CINZAS VOLANTES, COPRODUTO DA GASEIFICAÇÃO DO CARVÃO MINERAL DE CANDIOTARS. Anais do Salão Internacional de Ensino, Pesquisa e Extensão, v. 8, n. 2, 2017.

GUILHON, D.; SANTOS, D. M. S.; FARIAS, J. A. F. "AVALIAÇÃO DA CERÂMICA VERMELHA DE ROSÁRIO (MA) A PARTIR DA ADIÇÃO DE FINO DE ROCHAS ORNAMENTAIS." Blucher Design Proceedings 2.9 (2016): 4176-4187.

M. CIENTEC 1/C - 022 - Agosto 1976 - MATERIAIS CERÂMICOS: Ensaio de Absorção de Água, 1p.

M. CIENTEC 1/C - 023 - Agosto 1976 - MATERIAIS CERÂMICOS: Determinação Ade Porosidade aparente, $1 \mathrm{p}$.

M. CIENTEC 1/C - 022 - Agosto 1976 - MATERIAIS CERÂMICOS: Massa Específica Aparente, 1p.

NBR 15270-1: blocos cerâmicos para alvenaria de vedação: terminologia e Requisitos. Rio de Janeiro, 2005.

NBR 15310. Componentes cerâmicos - Telhas - Terminologia, requisitos e métodos de ensaio, Rio de Janeiro, 2009.

PELLEGRINO, R. Gaseificação de carvão mineral com adição de vapor e remoção de H2S, em leito fluidizado. 2006. 146 p. Dissertação (Mestrado em Engenharia Mecânica) Faculdade de Engenharia Mecânica, Departamento de Engenharia Térmica e Fluidos, Universidade Estadual de Campinas, Campinas, 2006.

PINHEIRO, B. C. A.; HOLANDA, J. N. F. Efeito da temperatura de queima em algumas propriedades mecânicas de cerâmica vermelha. Cerâmica, São Paulo, v. 56, n. 339, p. 237- 243, July 2010 Available from <http://www.scielo.br/scielo.php?script=sci_arttext\&pid=S036669132010000300005\&lng=en \&nrm=iso>. access on 12 Mar. 2017. http://dx.doi.org/10.1590/S036669132010000300005 .

SOARES, D. et al. "Gaseificação de serragem de madeira com vapor de água: estudo cinético." Scientia cum Industria 4.2 (2016): 119-124. 